\title{
Pre-service teachers' academic judgments of overweight students
}

\author{
Barbara C. N. Müller ${ }^{1}$ - Arnoud Oude Groote Beverborg ${ }^{2}$ • \\ Sabine Glock ${ }^{3}$
}

Received: 4 August 2016/Accepted: 17 July 2017/Published online: 13 September 2017

(C) The Author(s) 2017. This article is an open access publication

\begin{abstract}
Overweight children in schools can become victims of stereotyping and discrimination from both peers and teachers. Research on stereotypical expectations and impression and judgment formation has suggested that teachers might rely on their negative stereotypical expectations when judging students. In the present study, we experimentally investigated whether pre-service academic subject teachers' judgments about students were biased through stereotypical expectations about students' weights. Pre-service teachers were presented with a case report of an overweight- and a normal-weight student, and judged their academic performance and social skills. Results demonstrated that the overweight student was judged as performing better compared to his normal-weight counterpart academically while perceived social skills did not differ. Response latencies suggest that these findings relate to pre-service teachers' positive stereotypical beliefs about overweight students. These findings inspire to further investigate this surprising positivity bias and develop trainings for pre-service students to overcome other stereotypical expectations, which should ideally lead to evaluations based solely on actual academic performance and not stereotypical expectations, whether they are positive or negative.
\end{abstract}

Keywords Pre-service teachers - Stereotypical beliefs · Judgments · Dual process models

Barbara C. N. Müller

B.Muller@bsi.ru.nl

1 Behavioural Science Institute, Radboud University Nijmegen, P.O. Box 9104, 6500 HE Nijmegen, The Netherlands

2 Johannes-Gutenberg Universität Mainz, Mainz, Germany

3 Bergische Universität Wuppertal, Wuppertal, Germany 


\section{Introduction}

Overweight and obesity is a growing problem in the western world and linked to diseases such as diabetes and cancer, as well as cardiovascular diseases (World Health Organization 2013). But not only is obesity and overweight a health problem, overweight individuals also experience problems in the form of social stigmatization-with overweight children in schools becoming victims of stereotyping and discrimination from both peers and teachers (Neumark-Sztainer et al. 2002; Puhl and Brownell 2006; Warschburger 2005). Research has suggested that overweight students reach a lower educational level than their normal-weight peers (e.g., Latinen et al. 2002), and that the negative stereotyping of teachers might be related to this lower performance, for example through more negative comments during class against overweight students (Puhl and Heuer 2009). The present study aimed to experimentally investigate whether teachers' stereotypical expectations about students with overweight influence teachers' academic judgments about these students.

\subsection{Academic consequences of negative stereotyping}

Stereotypical expectations about overweight people are widespread, with overweight people being perceived as lazy, unsuccessful, and unintelligent (e.g., Puhl and Heuer 2009). Research on stereotypes about overweight students in the classroom has mainly focused on physical education teachers, as they are involved and should play a pivotal role in the prevention and treatment of overweight and obesity (O'Brien et al. 2007; Savage 1995). It has been shown that physical education teachers see overweight students as being less successful than their normal-weight peers (Neumark-Sztainer et al. 1999) and pre-service physical education teachers expressed strong beliefs that overweight students were lazier than normal-weight students (Chambliss et al. 2004). In addition, these studies show that very often children themselves were held largely responsible for their overweight (Greenleaf and Weiller 2005; Neumark-Sztainer et al. 1999) and were perceived as less socially competent than normal-weight students (Greenleaf and Weiller 2005). Although sports may be the subject related strongly to overweight, teachers from other subjects might hold stereotypical expectations as well. In line with this, research among pre-service teachers preparing for various educational subjects has found a bias against obesity and overweight (Walter et al. 2013) and even physical education teachers express lower expectations regarding the reasoning ability of overweight students (Greenleaf and Weiller 2005).

It has been suggested that those negative stereotypical expectations might promote prejudice and discrimination (Puhl and Heuer 2010). In line with this assumption, research has demonstrated that being overweight is linked to higher absenteeism in school (Geier et al. 2007), and that the chances to develop personally at school decrease with an increase in body weight (Puhl and Heuer 2009), while the likelihood of being held back a grade increases (Falkner et al. 2001; Shore et al. 2008). Furthermore, it has been observed that overweight students are more likely to 
be referred to special education compared to normal-weight students (e.g., Tershakovec et al. 1994), and this negative trend continues in higher education, with overweight students being less likely accepted to college (Crandall 1991). Differences in performance disappeared after controlling for socioeconomic status and ethnicity, thus these negative consequences could partly be the result of variables associated with overweight and obesity (Datar et al. 2004).

As these studies are predominantly correlational (see Taras and Potts-Datema 2005), we designed an experiment to investigate whether pre-service teachers' negative stereotypical expectations contribute to their academic judgment of the performance of overweight students. Since pre-service teachers are future teachers, it seems of high importance to investigate whether they enter the classroom with negative stereotypical expectations about overweight students. Pre-service teachers might then already be trained during their academic studies to overcome stereotypical biases. Thus, focussing on pre-service teachers is vital to improve a fair treatment of all students, independent of their body weight.

\subsection{Theoretical background}

Stereotypical expectations have been considered in dual process models of impression and judgment formation (Brewer 1988; Fiske et al. 1999; Fiske and Neuberg 1990; Smith and Decoster 2000). These models suggest that people rely on their stereotypical expectations whenever possible. Those expectations often derive from very little information (e.g., Chang and Sue 2003; Jussim 1989; Rosenthal and Jacobson 1968) and they might determine how information about a person is processed and how this person is judged. Once stereotypical expectations are activated, they guide attention, information processing, inferences, and judgment (Smith 1998). This stereotype- or category-based information processing and judgment formation is fundamental (Smith and Decoster 2000) and assumed to be the default strategy (Fiske and Neuberg 1990), as this process is effortless and efficient (Macrae et al. 1994). Dual process models, however, specify that the occurrence of the stereotype-based strategy depends on the configuration of information about the person in question (Brewer 1988; Fiske and Neuberg 1990). Thus, only information that is consistent with stereotypical expectations is able to elicit stereotype-based judgment formation. In contrast, information about a person that is inconsistent with stereotypical expectations leads to information-integrating processing (Fiske and Neuberg 1990). This strategy is effortful, as people integrate attribute for attribute into their judgment, thereby reviewing carefully all available information (Fiske and Neuberg 1990). To this extend, the information-integration strategy often results in more accurate judgments (Tetlock and Kim 1987) because people rely more on the actual person information than on their stereotypical expectations. Nonetheless, because of the careful inspection of all available information, this strategy is more time-consuming (Hemsley and Marmurek 1982; Sherman et al. 1998) than the stereotype-based one.

Hence, people have two information processing strategies at hand depending on the person information configuration. Expectation-consistent person information is suggested to result in stereotype-based processing and judgments that are biased 
through activated expectations, while expectation-inconsistent information should result in information-integrating processing and more accurate judgments. Research has already demonstrated that teachers as well as pre-service teachers rely on stereotypical expectations when it comes to the academic judgment of negatively stereotyped students such as racial or ethnic minority students (Glock et al. 2013; Glock and Krolak-Schwerdt 2013; McCombs and Gay 1988; Parks and Kennedy 2007). This research implies that academic achievement judgments are not biased through race or ethnicity per se, but rather that students who confirm negative stereotypical expectations were judged according to the stereotype while students who did not behave stereotypically did not experience disadvantages because of their race or ethnicity (Glock and Krolak-Schwerdt 2013; Neal et al. 2003). This might lead to a vicious circle in which low performing students confirming the negative stereotype are evaluated more negatively, which in turn leads to a stronger confirmation of the stereotype and to even more negative evaluations.

\subsection{Research question}

Although research has provided evidence for racial or ethnic stereotypical expectations influencing academic achievement judgment, research has hardly considered teachers' academic achievement judgments of overweight students. Therefore, in the present study, we experimentally investigated whether pre-service teachers' academic judgments about students depended on the weight of the students and thus, were biased through stereotypical expectations. Corresponding to the theoretical framework outlined above, we expected that pre-service teachers' academic judgments were biased through their stereotypical expectations when student information was expectation-consistent and that their academic judgments were more accurate when student information was expectation-inconsistent. As overweight people are perceived as lazy, unsuccessful and unintelligent (e.g., Puhl and Heuer 2009), and this form of negative stereotyping is suggested to be socially accepted (Puhl and Heuer 2010), we assumed that a below-average student described as lethargic, performing poorly in the academic subjects, isolated, and not very popular in class, would provide expectation-consistent information about overweight students, but the same information would be expectation-inconsistent information about normal-weight students. On the other hand, a description of a student as interested, performing very well in the academic subjects, and connected with others, would be expectation-consistent information for a normal-weight student, but expectation-inconsistent for an overweight student.

Hence, half of the pre-service teachers read two case reports that both confirmed stereotypical expectations: one with information of an overweight below-average student and one of a normal-weight above-average student. The other half of preservice teachers read two case reports that both disconfirmed stereotypical expectations: one with information of an overweight above-average student and one with information of a normal-weight below-average student. After reading each case report, participants were asked to judge the students' academic performance on math and language, overall intelligence, as well as social skills and assertiveness (see also Glock and Krolak-Schwerdt 2013). Drawing on the research findings on 
the disadvantages of obese people and on dual process models of impression and judgment formation, we expected that pre-service teachers who read a case report about overweight students employed a stereotype-based information processing strategy. This should result in more unfavourable and faster academic judgments of the below-average student than of the normal-weight counterpart and this effect should be observable on all judgment dimensions. Accordingly, we expected that pre-service teachers who read a case report about above-average students would apply the information integrating strategy. Thus, no differences in the academic judgments and in judgment latencies should emerge between the above-average overweight student and his normal-weight counterpart.

\section{Method}

\subsection{Participants and design}

Fifty-seven pre-service teachers (54 female, age range 17-35 years) with a mean age of 20.98 years $(S D=5.83)$ participated in this study. All participants majored in academic subjects. Participants' teaching experience ranged from 1 to $470 \mathrm{~h}$. To explain the high teaching experience, it needs to be known that in the Netherlands where this study was conducted, pre-service teachers start already within their first year at the university with teaching classes to gain as much hands-on experience as possible. This is done in practical courses throughout the year. At the end of their studies, the teaching load increases. We designed this study as an online-study and emailed possible participants the link by which they could start the study. Email addresses were obtained from the University. To ensure that only pre-service teachers participated in the study, the email list only entailed undergraduates in education. Participation was voluntary. Participants received course credit for participation and, additionally, had the possibility to win one of two vouchers for an online shop worth 20 Euros (about US\$27). The experiment had a $2 \times 2$ mixed between-within factorial design with expectation-consistency (confirming vs. disconfirming) varying between participants and student weight (overweight vs. normal-weight) varying within participants. As no medical procedure was applied to participants, and no physical or psychological risks were associated with participation, no ethical approval was requested.

\subsection{Procedure and materials}

Participants could download the experiment from the Internet. Participants were then informed that this study would take about $20 \mathrm{~min}$ and that they should ensure that they were not disturbed and inattentive during those $20 \mathrm{~min}$. After giving informed consent, the experiment started with instructing participants that they were presented with case reports of two fictional students, and that their task was to read these reports carefully.

We randomly allocated participants to the different experimental conditions. Participants read either the stereotype-disconfirming case reports of an overweight 
male above-average student in class and a normal-weight male below-average student, or they were presented with the stereotype-confirming case reports of the normal-weight male above-average student in class and the overweight male belowaverage student. Which descriptions participants read was randomized and counterbalanced. The sentences of the case reports were presented one item at a time; when participants pressed the space key, the next item was presented.

The items for student descriptions were collected from earlier research (Glock and Krolak-Schwerdt 2013). For instance, the above-average student was described as industrious, performing well in school, and highly motivated. The case report for the below-average student was constructed in the same way. For instance, the belowaverage student did not perform well in school, was poorly integrated in class, and uninvolved in lessons. The items were framed as sentences, resulting in 17 sentences regarding items describing an above-average student and 17 sentences regarding items describing the below-average student (the case reports can be received by contacting the corresponding author). The below-average student was always called "Mathijs" and the above-average student was always called "Martijn". The case reports were adjusted in such a way that information about the weight of the student was provided: It was stated in the first sentence that the student was either overweight or was of normal weight. All other information was the same for the two the above-average case reports and the two below-average case reports.

After each case report, participants were asked to evaluate the students' characteristics on a 7-point Likert scale ranging from 1 (little present) to 7 (clearly present), presented as one-word or two-word items. Earlier research demonstrated the effectiveness of this measurement (Glock and Krolak-Schwerdt 2013). Judgments concerned academic competencies in math (one item called 'math competence'), Dutch language proficiency (three items called 'Dutch reading comprehension', 'Dutch writing knowledge', and 'Dutch language comprehension', Cronbach's $\alpha_{\text {below-average student }}=.98$, Cronbach's $\alpha_{\text {above-average student }}=.92$ ), intelligence (two items called 'intelligence' and 'information processing', $\mathrm{SB}_{\text {below-average student }}=.72$, $\mathrm{SB}_{\text {above-average student }}=.91$ ), social skills (two items covering social isolation and emotionality (fear), $\mathrm{SB}_{\text {below-average student }}=.50, \mathrm{SB}_{\text {above-average student }}=.59$ ), and assertiveness (two items covering active engagement and personal assertiveness, $\mathrm{SB}_{\text {below-average student }}=.42, \mathrm{SB}_{\text {above-average student }}=.53$ ) were assessed, as well as judgment latencies. Judgment latencies were measured from the moment an item was presented on the screen until the participant gave a response.

Subsequently, participants were asked for demographic data such as their age, gender, their academic studies, the school track they were on to prepare for teaching, and their instruction experience. In the end, participants were thanked and debriefed.

\section{Results}

\subsection{Judgment dimensions}

Five separate 2 (expectation-consistency: confirming vs. disconfirming) $\times 2$ (student weight: overweight vs. normal weight) mixed (between-within factorial) 
ANOVAs were conducted, with expectation-consistency as between-subjects factor, student weight as within-subjects factor, and the mean scores of the five dimensions math, Dutch language proficiency, intelligence, social skills, and assertiveness as dependent variables. Bonferroni comparisons were applied for post hoc analyses. Confirming means that participants saw these two case reports: one of a belowaverage overweight student and one of an above-average normal-weight student. Disconfirming means that participants saw these two case reports: one of a belowaverage normal-weight student and one of an above-average overweight student.

Because of the studies' design, only two comparisons were of interest for the different experimental conditions: (1) the comparison between the below-average overweight student and the below-average normal-weight student and (2) the comparison between the above-average overweight student and the above-average normal-weight student. All other comparisons were not relevant because they compared students with completely different academic achievement profiles and thus, had to become significant. Thus, we only report on the interaction effects. If applicable, Bonferroni corrected post hoc analyses were applied.

\subsubsection{Maths competency}

ANOVA revealed a significant interaction between expectation-consistency and student weight, $F(1,55)=4.41, p=.040, \eta_{\mathrm{p}}^{2}=.074$. Post-hoc comparisons revealed that for the above-average students, the overweight student $(M=6.56$, $S D=.86$ ) was evaluated as more competent in maths than the normal-weight student $(M=5.83, S D=1.44), \quad F(1,55)=5.81, \quad p=.019, \quad \eta_{\mathrm{p}}^{2}=.096 \quad$ (see Fig. 1a). This difference was not found for the below-average students, $F(1$, 55) $=1.84, p=.18, \eta_{\mathrm{p}}^{2}=.032$.

\subsubsection{Dutch language proficiency}

ANOVA yielded a significant interaction between expectation-consistency and student weight, $F(1,55)=11.04, p=.002, \eta_{\mathrm{p}}^{2}=.167$. Post-hoc comparisons revealed that for the above-average students, the overweight student $(M=6.43$, $S D=.58)$ was evaluated as more proficient in language than the normal-weight student $(M=5.59, S D=1.31), F(1,55)=10.79, p=.002, \eta_{\mathrm{p}}^{2}=.164$. For the below-average students, the same difference between the overweight $(M=3.65$, $S D=1.53)$ and the normal-weight student $(M=2.85, S D=.95)$ was observed, $F(1,55)=5.95, p=.018, \eta_{\mathrm{p}}^{2}=.098$ (see Fig. 1b).

\subsubsection{Intelligence}

A significant interaction between expectation-consistency and student weight was found, $F(1,55)=5.59, p=.022, \eta_{\mathrm{p}}^{2}=.092$. Post-hoc comparisons revealed that for the above-average students, the overweight student $(M=6.69, S D=.49)$ was evaluated as more intelligent than the normal-weight student $(M=6.17$, $S D=1.31), \quad F(1,55)=4.40, \quad p=.040 ; \eta_{\mathrm{p}}^{2}=.074$. For the below-average 
Fig. 1 Evaluations in a math, b language, and c intelligence, as a function of student weight (overweight vs. normal-weight) and expectation-consistency (below-average vs. aboveaverage)
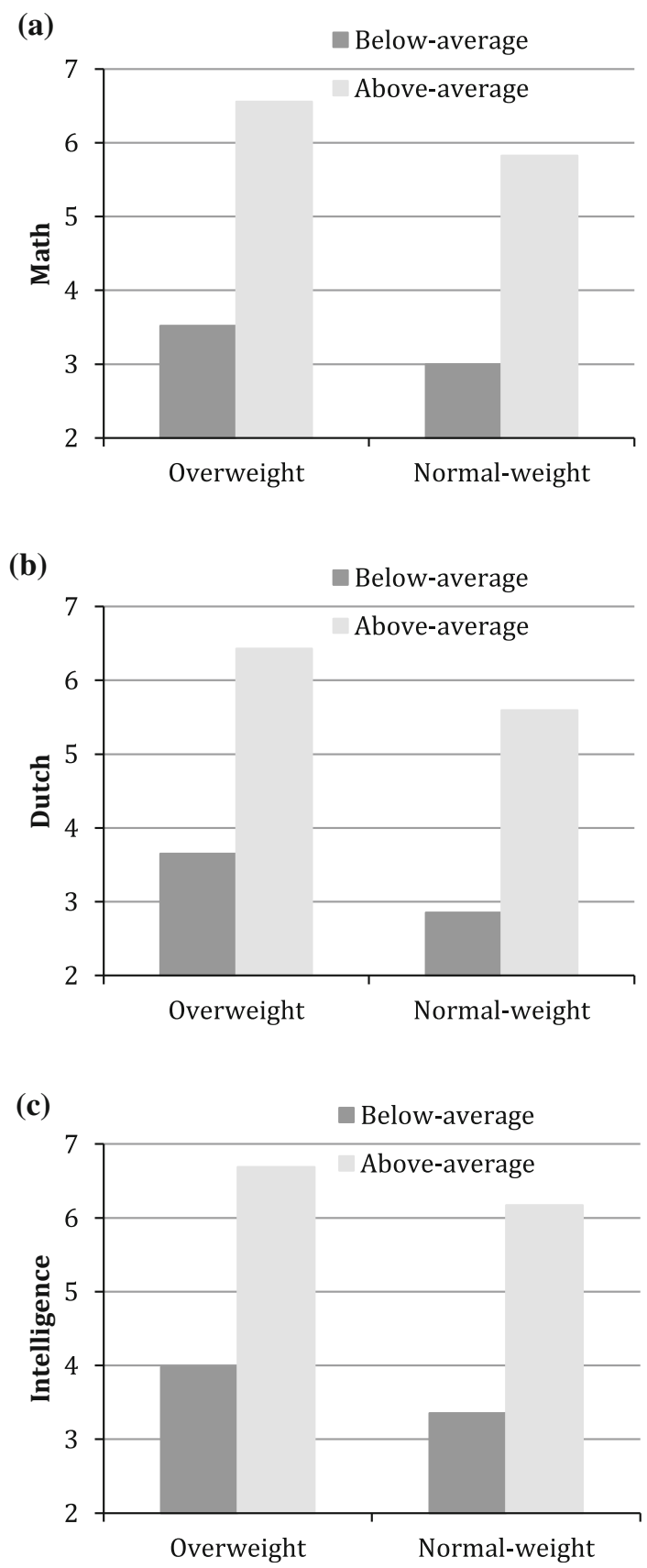

students, the same difference between the overweight $(M=3.98, S D=1.40)$ and the normal-weight student $(M=3.35, S D=.85)$ was found, $F(1,55)=4.40$, $p=.040 ; \eta_{\mathrm{p}}^{2}=.074$ (see Fig. 1c). 


\subsubsection{Social skills}

The interaction between expectation-consistency and student weight did not reach significant $F(1,55)=1.04, p=.31, \eta_{\mathrm{p}}^{2}=.019$.

\subsubsection{Assertiveness}

The interaction did not reach significance, $\left.F(1,55)=2.61, p=.11, \eta_{\mathrm{p}}^{2}=.045\right)$.

\subsection{Correlations between academic judgments}

To provide the reader with a full understanding of the data, we explored the relationships between the different judgements in more detail. Exploratory correlations were calculated for the below-average student and the above-average student separately. For both student descriptions, academic performance in math, language, and intelligence correlated positively. Furthermore, these three measures also correlated positively with assertiveness, as students seen as better in math, better in language, and being more intelligent were also evaluated as more assertive. Social skills correlated negatively with all other academic judgments for both the above-average student and for the below-average student, meaning that the less isolated a student was perceived, the higher the academic judgments were in math, language, intelligence, and assertiveness (see Tables 1,2 for all correlations).

Table 1 Correlations between judgment dimensions (Pearson correlation) for the below-average student

\begin{tabular}{|c|c|c|c|c|c|}
\hline $\begin{array}{l}\text { Below-average } \\
\text { student }\end{array}$ & $\begin{array}{l}\text { Math } \\
\text { competence }\end{array}$ & $\begin{array}{l}\text { Dutch } \\
\text { proficiency }\end{array}$ & Intelligence & $\begin{array}{l}\text { Social } \\
\text { skills }\end{array}$ & Assertiveness \\
\hline Math competence & 1 & & & & \\
\hline Dutch proficiency & $.624 * *$ & 1 & & & \\
\hline Intelligence & $.730 * *$ & $.682 * *$ & 1 & & \\
\hline Social skills & $-.445^{* *}$ & $-.394 * *$ & $-.454 * *$ & 1 & \\
\hline Assertiveness & $.516^{* *}$ & $.415 * *$ & $.533^{* *}$ & $-.387 * *$ & 1 \\
\hline
\end{tabular}

** Correlation is significant at the .01 level (2-tailed)

Table 2 Correlations between judgment dimensions (Pearson correlation) for the above-average student

\begin{tabular}{lllcll}
\hline $\begin{array}{l}\text { Above-average } \\
\text { student }\end{array}$ & $\begin{array}{l}\text { Math } \\
\text { competence }\end{array}$ & $\begin{array}{l}\text { Dutch } \\
\text { proficiency }\end{array}$ & Intelligence & $\begin{array}{l}\text { Social } \\
\text { skills }\end{array}$ & Assertiveness \\
\hline Math competence & 1 & & & & \\
Dutch proficiency & $.540^{* *}$ & 1 & 1 & & \\
Intelligence & $.523^{* *}$ & $.828^{* *}$ & $-.440^{* *}$ & 1 & \\
Social skills & $-.440^{* *}$ & $-.434^{* *}$ & $.555^{* *}$ & $-.564^{* *}$ & 1 \\
Assertiveness & $.494^{* *}$ & $.505^{* *}$ & & & \\
\hline
\end{tabular}

** Correlation is significant at the .01 level (2-tailed) 


\subsection{Judgment latencies}

\subsubsection{Maths competency}

Judgment latencies in ms were submitted to an ANOVA, which revealed a significant interaction between expectation-consistency and student weight, $F(1$, $\left.55)=8.96, p=.004, \eta_{p}^{2}=.140\right)$. For the above-average students, participants made faster judgments for the overweight $(M=2310, S D=1098)$ than for the normal-weight student $(M=2992, S D=1686), \quad F(1,55)=3.43 p=.069$, $\eta_{\mathrm{p}}^{2}=.059$. For the below-average students, participants tended to make faster judgments of the overweight $(M=2678, S D=1187)$ than the normal-weight students $(M=3630, S D=1755), F(1,55)=5.15, p=.027, \eta_{\mathrm{p}}^{2}=.086$.

\subsubsection{Dutch language proficiency}

ANOVA yielded a significant interaction between expectation-consistency and student weight, $F(1,55)=8.18, p=.006, \eta_{\mathrm{p}}^{2}=.130$. For the above-average students, participants made faster judgments of the overweight $(M=2678$, $S D=1340)$ than of the normal-weight student $(M=4119, S D=1947), F(1$, $55)=10.98, p=.002, \eta_{\mathrm{p}}^{2}=.166$. For the below-average students, we found no differences in judgments latencies between the overweight $(M=3193, S D=1256)$ and the normal-weight student $(M=3588, S D=2190), F(1,55)=.61, p=.439$, $\eta_{\mathrm{p}}^{2}=.01$.

\subsubsection{Intelligence}

A marginally significant interaction between expectation-consistency and student weight was found, $F(1,55)=3.62, p=.062, \eta_{\mathrm{p}}^{2}=.062$. For the above-average students, participants made faster judgments of the overweight $(M=3343$, $S D=1604)$ than of the normal-weight student $(M=4605, S D=1891), F(1$, $55)=7.33, p=.009, \eta_{\mathrm{p}}^{2}=.118$. For the below-average students, there was no difference in judgment latencies between the overweight $(M=5542, S D=1938)$ and the normal-weight student $(M=6062, S D=3507), F(1,55)=.42, p=.52$, $\eta_{\mathrm{p}}^{2}=.008$.

\subsubsection{Social skills}

The interaction failed to reach significance, $F(1,55)=2.85, p=.10, \eta_{\mathrm{p}}^{2}=.049$.

\subsubsection{Assertiveness}

The interaction did not reach significance, $\left.F(1,55)=.91, p=.34, \eta_{\mathrm{p}}^{2}=.016\right)$. 


\section{Discussion}

In the present study, we experimentally investigated whether pre-service teachers' academic judgments about students depended on the weight of the students and thus, were biased through stereotypical expectations. Drawing on dual process models of impression and judgment formation (Brewer 1988; Fiske et al. 1999; Fiske and Neuberg 1990), we expected that pre-service teachers who were confronted with expectation-consistent information about overweight students employed a stereotype-based information processing strategy resulting in more unfavourable and faster judgments of the below-average student than of the normalweight counterpart on all judgment dimensions. Accordingly, we expected that preservice teachers who were confronted with expectation-inconsistent student information would apply the information integrating strategy, resulting in that no differences in the academic judgments and in judgment latencies should emerge between the above-average overweight student and his normal-weight counterpart.

Surprisingly, independently of whether the information given to the pre-service teachers was expectation-consistent or expectation-inconsistent, overweight students were consistently judged as scoring higher in maths, having higher language proficiency, and as more intelligent than their normal-weight counterparts. When looking at the response latencies, it seems that this is partly due to faster judgments for the overweight student compared to the normal-weight student, at least when he performs above average. Thus, pre-service teachers in the present study seemingly rely on automatically activated stereotypical judgements. For the below-average student, faster responses for judging the overweight student were only found for math performance. No significant differences were found on judgments and judgment latencies concerning social skills and assertiveness. Interestingly, however, correlations suggest that there is a relationship between academic judgments and social judgments: both for the below-average student and for the above-average student, the higher academic judgments were, the more engaged and the less socially isolated students were perceived. It could be speculated whether pre-service teachers are worse in judging students on social dimensions, as they lack the in-class experience, while they are well trained to judge academic performance. This could at least partly explain the low internal consistencies for the social skills and assertiveness items. Another possibility might be that the reports presented did not adequately display social competences. Because of these low internal consistencies, results should be taken with caution and further research is needed to investigate this question.

Our findings that overweight students are judged more favourably and that this also relates to more positive social impressions suggest that-contrarily to previous research-stereotypical expectations about obese students are quite positive, particularly in relation to academic achievement. This assumption is supported by our findings regarding judgment latencies, which decreased for the judgments of the above-average student. Since research has shown that stereotypical expectations operate quite automatically when activated (Macrae et al. 1994) and this automaticity results in faster judgments (Smith et al. 1988; Smith and Lerner 
1986), we conclude that pre-service teachers expected overweight students to academically perform above the average. Thus, pre-service teachers applied the stereotype-based strategy depending on the weight of the student. To this extend, our assumption regarding stereotype-inconsistent and stereotype-consistent information about overweight students-although derived from previous research on obesity-did not hold, as pre-service teachers generally judged the overweight student more favourably. This might have several reasons. It might be that our participants simply do not hold negative stereotypical expectations towards overweight students. Research has shown that a positivity bias towards thinness is more likely responsible for often found anti-obesity biases (Glock et al. 2016; Roddy et al. 2010). However, if this explanation holds, we should have found more favourable academic judgments of normal-weight students. Future research is needed to investigate these differences in findings.

Although research suggested that obesity bias is a socially accepted form of negativity bias (Puhl and Heuer 2010), our participants might also be highly intrinsically motivated to control their negative stereotypes against overweight students, which enabled them to minimise the influence of stereotypical expectations on their judgments (see also Gordijn et al. 2004). Such high intrinsic motivation to control stereotypical thinking has already been observed among preservice teachers (Glock et al. 2016). Intrinsic motivation to suppress stereotypes leads to chronic stereotype suppression and faster responses to stereotype inconsistent information (Wyer et al. 2000). Furthermore, a high intrinsic motivation to suppress stereotypes can lead to automatic inhibition of negative stereotypes, and as such is a useful tool to reduce stereotypes (Monteith et al. 1998; Moskowitz et al. 1999; Wyer et al. 2000). Stereotype suppression can result in the affirmation of the counter-stereotype (Gawronski et al. 2008), which we might have observed in our data. Therefore, future research should apply a free-association paradigm in order to shed light on the content of stereotypical expectations about overweight students and investigate the automaticity of this content, for example by using a lexical decision task, which is suggested to assess activated stereotypical expectations (Baldwin et al. 1993; Fazio 2001). Moreover, including a measure of intrinsic motivation to control stereotypes might also prove valuable.

\subsection{Limitations}

There are some limiting aspects of our study that should be addressed. Because teachers and pre-service teachers tend to judge male students less favourably than female students (Maniadaki et al. 2003; Parks and Kennedy 2007), we suggested that stereotypical expectations were more pronounced for male students and thus, did not provide information about female students. Furthermore, recent research shows that gender differences, at least in minority groups, are more complex and depend on school level and the teacher's gender (see Glock and Klapproth 2017). Future research should investigate whether our findings can be replicated or whether pre-service teachers apply negative overweight-related stereotypical expectations when they judge female students. In the case of overweight students, female students are more vulnerable to social stigmatization related to overweight 
than male students (Crosnoe 2007). Moreover, lower academic performance is more frequently observed among female overweight students than among male overweight students (Sargent and Blanchflower 1995), even though female normal-weight students' academic achievement is superior to male students (for an overview see Voyer and Voyer 2014). Additionally, most of our participants were female. In further research, academic judgments of male pre-service teachers should be taken into account.

Secondly, academic judgments could at least partly depend on teachers' own BMI, which was not assessed in the present study. Research on the influence of persons' own body weight on the perception of overweight people is inconsistent: it either suggests that a person's own body weight is not related to their values and beliefs about overweight people (Crandall 1994) or that it is (Degner and Wentura 2009). Thus, the relationship between own BMI of teachers and pre-service teachers and academic judgments of overweight students should be investigated in the future, as this relationship might reflect in-group favouritism often observed in judgments (Brewer 1999). In addition, as the class situation in daily life is more demanding for teachers than the present study (in which academic judgments could be given without real interaction and possible distracting factors), observing teachers' behaviour in the classroom interaction would be furthermore advisable to validate the present findings. By doing so, not only academic judgments but also the possible relationship with social skills could be investigated.

Another factor that might prove valuable to be investigated in future research is related to the environment of teachers and pre-service teachers. Research has shown that in schools with higher rates of overweight students, social stigmatisation of overweight students decreases (Crosnoe 2007), and that more frequent contact with overweight people results in a change of visual preferences toward overweight people (Robinson and Christiansen 2014). Thus, the environment of pre-service teachers might contribute to their academic judgments of overweight students by making them more favourable because they frequently encounter overweight students. It might therefore be valuable to assess these processes in future research.

\subsection{Conclusions}

Our research provides first and important insights into stereotypical expectations of pre-service teachers about overweight students. The more favourable academic judgments we found regarding overweight students stand, nevertheless, in contrast to a fair treatment of all students. This implies that teacher education programs should focus on judgment formation processes: initiating self-reflective processes among pre-service teachers, for example by providing them with knowledge about biases in social judgment formation and how they could prevent them, might ensure the fair treatment of all students. Engagement in reflection has been found to have a positive influence on self-efficacy beliefs (Oude Groote Beverborg et al. 2015). In this case, self-reflection might boost teachers' expectation to be efficacious in judging students fairly on merits and not on appearance. With practice, this might transfer to one's efficacy beliefs about the capacity to apply data-driven decision making, aimed at improving one's teaching (Bandura 1997; Schwarzer and Hallum 
2008; Staman et al. 2014). Teaching pre-service teachers about the factors that might play a role in judgment formation such as stereotypes, attitudes, and particular student characteristics can help to increase their awareness of biasing factors (Pendry et al. 2007). This state of high self-focus induces people to suppress stereotypes (Macrae et al. 1998) and with sufficient practice (Monteith et al. 1998) in the safe environment of the university, pre-service teachers might be able to overcome stereotypical biases, which might, in turn, lead to a fairer academic judgment of students.

Acknowledgements We would like to thank Marianne Reuling-Schappin and Nora Loretan for their help in contacting the pre-service teachers of the ALPO studies at Radboud University Nijmegen. This research received no specific grant from any funding agency in the public, commercial or not-for-profit sectors.

Open Access This article is distributed under the terms of the Creative Commons Attribution 4.0 International License (http://creativecommons.org/licenses/by/4.0/), which permits unrestricted use, distribution, and reproduction in any medium, provided you give appropriate credit to the original author(s) and the source, provide a link to the Creative Commons license, and indicate if changes were made.

\section{References}

Baldwin, M. W., Fehr, B., Keedian, E., Seidel, M., \& Thomson, D. W. (1993). An exploration of the relational schemata underlying attachment styles: Self-report and lexical decision approaches. Personality and Social Psychology Bulletin, 19, 746-754. doi:10.1177/0146167293196010.

Bandura, A. (1997). Self-efficacy: The exercise of control. New York: Freeman.

Brewer, M. B. (1988). A dual process model of impression formation. In R. S. Wyer \& T. K. Srull (Eds.), Advances in social cognition (pp. 1-36). Hillsdale, NJ: Erlbaum.

Brewer, M. B. (1999). The psychology of prejudice: Ingroup love or outgroup hate? Journal of Social Issues, 55, 429-444.

Chambliss, H. O., Finley, C. E., \& Blair, S. N. (2004). Attitudes toward obese individuals among exercise science students. Medicine and Science in Sports and Exercise, 36, 468-474. doi:10.1249/01.MSS. 0000117115.94062.E4

Chang, D. F., \& Sue, S. (2003). The effects of race and problem type on teachers' assessments of student behavior. Journal of Consulting and Clinical Psychology, 71, 235-242. doi:10.1037/0022-006X.71. 2.235 .

Crandall, C. S. (1991). Do heavy-weight students have more difficulty paying for college? Personality and Social Psychology Bulletin, 17, 606-611. doi:10.1177/0146167291176002.

Crandall, C. S. (1994). Prejudice against fat people: Ideology and self-interest. Journal of Personality and Social Psychology, 66, 882-894. doi:10.1037//0022-3514.66.5.882.

Crosnoe, R. (2007). Gender, obesity, and education. Sociology of Education, 80, 241-260.

Datar, A., Sturm, R., \& Magnabosco, J. L. (2004). Childhood overweight and academic performance: National study of kindergartners and first-graders. Obesity Research, 12, 58-68. doi:10.1038/oby. 2004.9.

Degner, J., \& Wentura, D. (2009). Not everybody likes the thin and despises the fat: One's weight matters in the automatic activation of weight-related social evaluations. Social Cognition, 27, 202-221.

Falkner, N. H., Neumark-Sztainer, D., Story, M., Jeffery, R. W., Beuhring, T., \& Resnick, M. D. (2001). Social, educational, and psychological correlates of weight status in adolescents. Obesity Research, 9, 32-42. doi:10.1038/oby.2001.5.

Fazio, R. H. (2001). On the automatic activation of associated evaluations: An overview. Cognition and Emotion, 15, 115-141. doi:10.1080/0269993004200024. 
Fiske, S. T., Lin, M., \& Neuberg, S. L. (1999). The continuum model. Ten years later. In S. Chaiken \& Y. Trope (Eds.), Dual process theories in social psychology (pp. 231-254). New York: Guilford Press.

Fiske, S. T., \& Neuberg, S. L. (1990). A continuum of impression formation from category-based to individuating processes: Influences of information and motivation on attention and interpretation. In M. P. Zanna (Ed.), Advances in Experimental Social Psychology (Vol. 23, pp. 1-74). New York: Academic Press.

Gawronski, B., Deutsch, R., Mbirkou, S., Seibt, B., \& Strack, F. (2008). When "Just Say No" is not enough: Affirmation versus negation training and the reduction of automatic stereotype activation. Journal of Experimental Social Psychology, 44, 370-377. doi:10.1016/j.jesp.2006.12.004.

Geier, A. B., Foster, G. D., Womble, L. G., McLaughlin, J., Borradaile, K. E., Nachmani, J., et al. (2007). The relationship between relative weight and school attendance among elementary schoolchildren. Obesity, 15, 2157-2161. doi:10.1038/oby.2007.256.

Glock, S., \& Klapproth, F. (2017). Bad boys, good girls? Implicit and explicit attitudes towards ethinic minority students among elementary and secondary school teachers. Studies in Educational Evaluation, 53, 77-86. doi:10.1016/j.stueduc.2017.04.002.

Glock, S., \& Krolak-Schwerdt, S. (2013). Does nationality matter? The impact of stereotypical expectations on student teachers' judgments. Social Psychology of Education, 16, 111-127. doi:10. 1007/s11218-012-9197-z.

Glock, S., Krolak-Schwerdt, S., Klapproth, F., \& Böhmer, M. (2013). Beyond judgment bias: How students' ethnicity and academic profile consistency influence teachers' tracking judgments. Social Psychology of Education, 16, 555-573. doi:10.1007/s11218-013-9227-5.

Glock, S., Oude Groote Beverborg, A., \& Müller, B. C. N. (2016). Pre-service teachers' implicit and explicit attitudes toward obesity: The Role of intrinsic motivation to respond without prejudice. Social Psychology of Education, 19, 97-115. doi:10.1007/s11218-015-9315-9.

Gordijn, E. H., Hindriks, I., Koomen, W., Dijksterhuis, A., \& Van Knippenberg, A. (2004). Consequences of stereotype suppression and internal suppression motivation: A self-regulation approach. Personality and Social Psychology Bulletin, 30, 212-224. doi:10.1177/0146167203259935.

Greenleaf, C., \& Weiller, K. (2005). Perceptions of youth obesity among physical educators. Social Psychology of Education, 8, 407-423. doi:10.1007/s11218-005-0662-9.

Hemsley, G. D., \& Marmurek, H. H. C. (1982). Person memory: The processing of consistent and inconsistent person information. Personality and Social Psychology Bulletin, 8, 433-438. doi:10. $1177 / 0146167282083007$.

Jussim, L. (1989). Teacher expectations: Self-fulfilling prophecies, perceptual biases, and accuracy. Journal of Personality and Social Psychology, 57, 469-480. doi:10.1037//0022-3514.57.3.469.

Latinen, J., Power, C., Ek, E., Sovio, U., \& Järvelin, M. R. (2002). Unemployment and obesity among young adults in a northern Finland 1966 birth cohort. International Journal of Obesity, 26, 1329-1338. doi:10.1038/sj.ijo.0802134.

Macrae, C. N., Bodenhausen, G. V., \& Milne, A. B. (1998). Saying no to unwanted thoughts: Self-focus and the regulation of mental life. Journal of Personality and Social Psychology, 74, 578-589. doi:10.1037//0022-3514.74.3.578.

Macrae, C. N., Milne, A. B., \& Bodenhausen, G. V. (1994). Stereotypes as energy-saving devices: A peek inside the cognitive toolbox. Journal of Personality and Social Psychology, 66, 37-47. doi:10.1037// 0022-3514.66.1.37.

Maniadaki, K., Sonuga-Barke, E. J. S., \& Kakouros, E. (2003). Trainee nursery teachers' perceptions of disruptive behaviour disorders; the effect of sex of child on judgements of typicality and severity. Child: Care, Health and Development, 29, 433-440. doi:10.1046/j.1365-2214.2003.00362.x.

McCombs, R. C., \& Gay, J. (1988). Effects of race, class, and IQ information on judgments of parochial grade school teachers. The Journal of Social Psychology, 128, 647-652. doi:10.1080/00224545. 1988.9922918.

Monteith, M. J., Sherman, J. W., \& Devine, P. G. (1998). Suppression as a stereotype control strategy. Personality and Social Psychology Review, 2, 63-82. doi:10.1207/s15327957pspr0201_4.

Moskowitz, G. B., Gollwitzer, P. M., Wasel, W., \& Schaal, B. (1999). Preconscious control of stereotype activation through chronic egalitarian goals. Journal of Personality and Social Psychology, 77, 167-184. doi:10.1037//0022-3514.77.1.167.

Neal, L. I., McCray, A. D., Webb-Johnson, G., \& Bridgest, S. T. (2003). The effects of African American movement styles on teachers' perceptions and reactions. The Journal of Special Education, 37, 49-57. doi:10.1177/00224669030370010501. 
Neumark-Sztainer, D., Falkner, N., Story, M., Perry, C., Hannan, P. J., \& Mulert, S. (2002). Weightteasing among adolescents: Correlations with weight status and disordered eating behaviors. International Journal of Obesity, 26, 123-131. doi:10.1038/sj.ijo.0801853.

Neumark-Sztainer, D., Story, M., \& Harris, T. (1999). Beliefs and attitudes about obesity among teachers and school health care providers working with adolescents. Journal of Nutrition Education, 31, 3-9. doi:10.1016/S0022-3182(99)70378-X.

O'Brien, K. S., Hunter, J. A., \& Banks, M. (2007). Implicit anti-fat bias in physical educators: Physical attributes, ideology and socialization. International Journal of Obesity, 31, 308-314. doi:10.1038/sj. ijo.0803398.

Oude Groote Beverborg, A., Sleegers, P. J. C., Endedijk, M. D., \& van Veen, K. (2015). Towards sustaining levels of reflective learning: How do transformational leadership, task interdependence, and self-efficacy shape teacher learning in schools? Societies. doi:10.3390/soc5010187.

Parks, F. R., \& Kennedy, J. H. (2007). The impact of race, physical attractiveness, and gender on education majors' and teachers' perceptions of student competence. Journal of Black Studies, 37, 936-943. doi:10.1177/0021934705285955.

Pendry, L. F., Driscoll, D. M., \& Field, S. C. T. (2007). Diversity training: Putting theory into practice. Journal of Occupational and Organizational Psychology, 80, 27-50. doi:10.1348/ $096317906 \mathrm{X} 118397$.

Puhl, R. M., \& Brownell, K. D. (2006). Confronting and coping with weight stigma: An investigation of overweight and obese adults. Obesity, 14, 1802-1815. doi:10.1038/oby.2006.208.

Puhl, R. M., \& Heuer, C. A. (2009). The stigma of obesity: A review and update. Obesity, 17, 941-964. doi:10.1038/oby.2008.636.

Puhl, R. M., \& Heuer, C. A. (2010). Obesity stigma: Important considerations for public health. American Journal of Public Health, 100, 1019-1028. doi:10.2105/AJPH.2009.159491.

Robinson, E., \& Christiansen, P. (2014). The changing face of obesity: Exposure to and acceptance of obesity. Obesity, 22, 1380-1386. doi:10.1002/oby.20699.

Roddy, S., Stewart, I., \& Barnes-Holmes, D. (2010). Anti-fat, pro-slim, or both? Using two reaction-time based measures to assess implicit attitudes to the slim and overweight. Journal of Health Psychology, 15, 416-425. doi:10.1177/1359105309350232.

Rosenthal, R., \& Jacobson, L. (1968). Pygmalion in the classroom. New York: Holt, Rinehart, and Winston.

Sargent, J. D., \& Blanchflower, D. G. (1995). Obesity and stature in adolescence and earnings in young adulthood: Analysis of a British cohort. Archives of Pediatrics and Adolescent Medicine, 148, 681-687.

Savage, M. P. (1995). Percpetion of childhood obesity of undergraduate students in physical education. Psychological Reports, 76, 1251-1259. doi:10.2466/pr0.1995.76.3c.1251.

Schwarzer, R., \& Hallum, S. (2008). Perceived teacher self-efficacy as a predictor of job stress and burnout: Mediation analyses. Applied Psychology: An International Review, 57, 152-171. doi:10. 1111/j.1464-0597.2008.00359.x.

Sherman, J. W., Lee, A. Y., Bessenoff, G. R., \& Frost, L. A. (1998). Stereotype efficiency reconsidered: Encoding flexibility under cognitive load. Journal of Personality and Social Psychology, 75, 589-606. doi:10.1037//0022-3514.75.3.589.

Shore, S. M., Sachs, M. L., Lidicker, J. R., Brett, S. N., Wright, A. R., \& Libonati, J. R. (2008). Decreased scholastic achievement in overweight middle school students. Obesity, 16, 1535-1538. doi:10.1038/ oby.2008.254.

Smith, E. R. (1998). Mental representation and memory. In D. T. Gilbert, S. T. Fiske, \& G. Lindzey (Eds.), Handbook of social cognition (Vol. 1, pp. 391-445). New York, NY: McGraw-Hill.

Smith, E. R., Branscombe, N. R., \& Bormann, C. (1988). Generality of the effects of practice on social judgment tasks. Journal of Personality and Social Psychology, 54, 385-395. doi:10.1037//00223514.54.3.385.

Smith, E. R., \& Decoster, J. (2000). Dual-process models in social and cognitive psychology: Conceptual integration and links to underlying memory systems. Personality and Social Psychology Review, 4, 108-131. doi:10.1207/S15327957PSPR0402.

Smith, E. R., \& Lerner, M. (1986). Development of automatism of social judgments. Journal of Personality and Social Psychology, 30, 246-259. doi:10.1037//0022-3514.50.2.246.

Staman, L., Visscher, A. J., \& Luyten, H. (2014). The effects of professional development on the attitudes, knowledge and skills required for data-driven decision making. Studies in Educational Evaluation, 42, 79-90. doi:10.1016/j.stueduc.2013.11.002. 
Taras, H., \& Potts-Datema, W. (2005). Obesity and student performance at school. The Journal of School Health, 75, 291-295. doi:10.1111/j.1746-1561.2005.00040.x.

Tershakovec, A. M., Weller, S. C., \& Gallagher, P. R. (1994). Obesity, school performance and behaviour of black, urban elementary school children. International Journal of Obesity and Related Metabolic Disorders, 18, 323-327.

Tetlock, P. E., \& Kim, J. I. (1987). Accountability and judgment processes in a personality prediction task. Journal of Personality and Social Psychology, 52, 700-709. doi:10.1037//0022-3514.52.4.700.

Voyer, D., \& Voyer, S. D. (2014). Gender differences in scholastic achievement: A meta-analysis. Psychological Bulletin, 140, 1174-1204.

Walter, M. E., Ragan, K., Sulak, T. N., \& Bagby, J. H. (2013). Implicit and explicit biases toward obesity: Perspectives of school of education students. Community Medicine \& Health Education, 3, 212. doi:10.4172/2161-0711.1000212.

Warschburger, P. (2005). The unhappy obese child. International Journal of Obesity, 29, S127-S129. doi:10.1038/sj.ijo.0803097.

World Health Organization. (2013). Obesity and overweight. Retrieved from http://www.who.int/ mediacentre/factsheets/fs311/en/.

Wyer, N. A., Sherman, J. W., \& Stroessner, S. J. (2000). The roles of motivation and ability in controlling the consequences of stereotype suppression. Personality and Social Psychology Bulletin, 26, 13-25. doi:10.1177/0146167200261002.

Dr. Barbara C. N. Müller received her Ph.D. in 2013 from Radboud University, the Netherlands. Her research covers a wide array of topics such as human/non-human interaction, social influence, health communication, and stereotyping. Currently, she works as an assistant professor at the communication science department at the Behavioural Science Institute, Radboud University Nijmegen, the Netherlands.

Dr. Arnoud Oude Groote Beverborg received his Ph.D. 2015 at University Twente in Enschede, the Netherlands. His research focuses on sense making, life-long learning, and supportive environments for sustained improvements. Currently, he works as an assistant professor at the Centre for School Effectiveness and School Improvement at the Johannes-Gutenberg Universität Mainz, Germany.

Dr. Sabine Glock is working as a senior researcher in the Institute of Educational Research in the School of Education at the Bergische Universität Wuppertal, Germany. She is concerned with educational psychology, particularly, with educational decision making and factors influencing educational decisions regarding ethnic minority students. Her main research interest is implicit cognition, particularly implicit attitudes. 